\title{
Estratégias de Ensino e Recursos Pedagógicos para o Ensino de Alunos Com TDAH em Aulas de EducaÇão Física ${ }^{1}$ Teaching Strategies and Pedagogical ResourCes for Teaching Students WITH ADHD IN PHYSICAL EDUCATION CLASSES
}

\author{
Camila Rodrigues COSTA2 \\ Jaqueline Costa Castilho MOREIRA ${ }^{3}$ \\ Manoel Osmar SEABRA JÚNIOR ${ }^{4}$
}

\begin{abstract}
RESUMO: o Transtorno do Déficit de Atenção com Hiperatividade (TDAH) é um transtorno neurocomportamental, multifatorial, comum na população de crianças em idade escolar, cuja característica principal é um padrão persistente de desatenção e ou hiperatividade/impulsividade, que frequentemente resulta em prejuízos emocionais, sociais e sobretudo, funcionais. Nesta perspectiva, a pesquisa teve como objetivo planejar, aplicar e analisar um programa de intervenção, composto por atividades psicomotoras, lúdicas e jogos de estratégias, a partir da adaptação de recursos pedagógicos e estratégias de ensino utilizadas em aulas de Educação Física com intuito de estimular a memória, atenção e concentração de crianças com TDAH. Participaram do estudo quatro estudantes com diagnóstico, com idades entre seis e dez anos, de ambos os sexos, regularmente matriculados em uma escola de ensino regular. Para a coleta de dados inicialmente foi aplicada a EDM, com a finalidade de identificar a condição motora dos alunos. De posse dos dados obtidos e após uma análise documental, foram selecionados e aplicados três eixos temáticos de atividades: psicomotoras, lúdicas e jogos de estratégia. Os instrumentos utilizados foram: observação participante com registro de diário de campo e filmagem. Para análise dos dados foi utilizada a análise de conteúdo e, por conseguinte, obtidas seis categorias: 1. Vínculo professor/aluno e aluno/aluno; 2. Trabalho cooperativo; 3. Mediação; 4. Rotina; 5. Seleção do Recurso e 6. Ambiente. Estas categorias puderam nortear discussōes representativas de uma proposta de programa de Educação Física Inclusiva para estudantes com TDAH, em consonância com a possibilidade de instituir rotinas que possam integrar os estímulos de memória, atenção e concentração destes sujeitos.
\end{abstract}

PALAVRAS- CHAVE: Educação Especial. Educação Física Adaptada. Educação Inclusiva. Lúdico. Jogos Pedagógicos.

\begin{abstract}
ADHD is a common neurobehavioral, multifactorial disorder, that is common in the population of schoolage children, whose main feature is a persistent pattern of inattention and or hyperactivity/impulsivity, which often results in emotional, social and above all, functional impairments. In this perspective, the research aimed to plan, implement and analyze an intervention program consisting of psychomotor, play activities and game strategies. The study was based on the adaptation of learning resources and teaching strategies used in physical education classes aiming to stimulate memory, attention and concentration in children with ADHD. The study included four students diagnosed between the ages of six and ten years, of both genders, enrolled in a regular teaching school. The scale of motor development was initially applied for data collection, in order to identify the motor condition of the students. Having obtained the data and after a documentary analysis, three thematic types of activities were selected and applied: psychomotor, play activities and strategy games. The instruments used were: participant observation with field journal registration and filming. Content analysis was used for data analysis and six categories were obtained: 1. Teacher / student and student / student bond; 2. Cooperative Work.; 3. Mediation; 4. Routine; 5. Resource Selection and 6. Environment. These categories could underpin representative discussions of a proposal for an Inclusive Physical Education program for students with ADHD, consistent with the possibility of establishing routines that can integrate memory stimuli, attention and concentration of these subjects.
\end{abstract}

KEYWORDS: Special Education. Adapted Physical Education. Inclusive Education. Play. Pedagogical Games.

\footnotetext{
${ }^{1}$ Fonte financiamento: PIBIC/CNPq

${ }^{2}$ Licenciada em Educação Física pela Faculdade de Ciências e Tecnologia/Unesp, Presidente Prudente, mestranda do Programa de Pós-Graduação em Educação, Unesp, Marília. São Paulo, Brasil. r.camilacosta@gmail.com

${ }^{3}$ Professora Doutora do Departamento de Educaçâo Física da Faculdade de Ciências e Tecnologia/Unesp, Presidente Prudente, São Paulo, Brasil. jackycastilho@fct.unesp.br

${ }^{4}$ Professor Doutor do Departamento de Educação Física da Faculdade de Ciências e Tecnologia/Unesp, Presidente Prudente, São Paulo, Brasil.seabrajr@fct.unesp.br
} 


\section{INTRODUÇÃo}

O Transtorno de Déficit de Atenção e Hiperatividade/Impulsividade (TDAH) é um transtorno neurocomportamental, multifatorial, cuja característica principal é um padrão persistente de desatenção e ou hiperatividade/impulsividade, que frequentemente resulta em prejuízos emocionais, sociais e, sobretudo, funcionais (SILVA, 2009).

A tríade sintomática, na maior parte dos casos, é percebida após o ingresso do sujeito no ambiente escolar, uma vez que, nesse período, comportamentos característicos do transtorno ficam em evidência e resultam em dificuldades de aprendizagem ${ }^{5}$ (ROHDE; HALPERN, 2004a).

O diagnóstico do TDAH é fundamentalmente clínico, baseado em critérios provenientes de sistemas classificatórios estabelecidos pelo Manual Diagnóstico e Estatístico de Transtornos Mentais, em sua quarta edição (DSM-V, 2011) e pela Classificação Internacional de Doenças CID-10 (OMS,1993).

O DSM-V subdivide o TDAH em três tipos, quais sejam: a) TDAH com predomínio de sintomas de desatenção; b) TDAH com predomínio de sintomas de hiperatividade/ impulsividade; e, c) TDAH combinado (DSM-V, 2011). O manual propóe a necessidade de pelo menos seis sintomas de desatenção e/ou seis sintomas de hiperatividade/impulsividade para o diagnóstico de TDAH. A equipe multidisciplinar ${ }^{6}$ deve levar em consideração, além dos critérios, outros aspectos como a história, observaçáo do comportamento, relato de pais e professores sobre o desempenho da criança nos diversos ambientes que frequenta, em um período mínimo de seis meses. Este deve corresponder a um grau desadaptativo e ser inconsistente com o nível de desenvolvimento esperado para a idade do sujeito (ROHDE; HALPERN, 2004b).

A prevalência de diagnósticos pautados nos critérios plenos do DSM-V em crianças em idade escolar é de 3 a 6\% segundo Rohde et al. (1999) e Faraone et al. (2003). Dentre as características persistentes inerentes ao transtorno, as crianças ainda podem apresentar outras dificuldades associadas, como: dificuldades na comunicação falada e escrita, em memorizar, planejar, organizar e executar tarefas, dificuldades com relação às habilidades motoras como, coordenação motora global e fina, equilíbrio, lateralidade, organização espacial e temporal, uma vez que, a habilidade motora de crianças com TDAH tende a ser expressivamente inferior ao que espera em cerca de 30\% a 50\% dos casos avaliados (PEREIRA; ARAUJO; MATTOS, 2005).

Esses dados corroboram com os encontrados no estudo realizado por Suzuki, Gugelmim e Soares (2005), no qual os autores identificaram que crianças com TDAH possuem alterações consideráveis com relação ao equilíbrio estático e que tais alteraçôes influenciam negativamente no desenvolvimento motor, cognitivo e afetivo dos alunos.

\footnotetext{
${ }^{5}$ As dificuldades de aprendizagem geralmente são percebidas com o ingresso da criança no ensino formal e caracteriza-se por manifestaçôes significativas na aquisição e utilização da compreensão falada, auditiva, da leitura, da escrita e do raciocínio lógico. Sua causa pode estar associada a fatores intrínsecos e extrínsecos ao individuo e traz consequências em outros aspectos como na autorregulação do comportamento, percepção social, bem como na interação social (PAÍN, 1985).

${ }^{6}$ Equipe multidisciplinar corresponde a um conjunto de profissionais que possuem diferentes especializaçôes e que atuam colaborativamente por um objetivo comum. Em se tratando de Educação, mais especificamente de alunos com necessidades educativas especiais segundo a Declaração de Salamanca, faz-se necessário um conjunto de açóes a serem desempenhadas que não é apenas exclusividade do Ministério de Educação, ao contrário, envolve os atores escolares, a família, a comunidade, assim como organizaçôes voluntárias (UNESCO , 1994).
} 
Sabe-se que a Educação Física é uma disciplina que leva o aluno a refletir, por meio do movimento, suas açóes e necessidades frente às demandas da sociedade atual na qual este precisa posicionar-se. Do mesmo modo, a Educação Física Adaptada visa compreender necessidades e desenvolver capacidades, em suma, potencializar açóes para independência e autonomia em meio a suas competências sociais e educacionais, no caso específico das crianças com TDAH, estimular a memória, atenção e concentração por meio de estratégias de ensino ${ }^{7}$ e recurso pedagógico ${ }^{8}$.

No entanto, uma das questóes que surge e que necessita ser respondida é: como o professor pode conduzir sua prática pedagógica junto às crianças com TDAH que perpassa por momentos como iniciar, desenvolver e concluir tarefas?

O primeiro passo exige que o professor seja capaz de identificar as potencialidades e necessidades dos estudantes para equiparar oportunidades sem oferecer privilégios em detrimento das dificuldades em adaptar, adequadamente, sua prática pedagógica.

Neira (2003) afirma que a prática pedagógica do professor deve estar pautada na cooperação e a valorização dos estudantes com diagnóstico de TDAH e sugere que as atividades para crianças com TDAH necessitam ser sistematizadas e devem atuar contra a dificuldade de atenção, concentração e memória.

Estudos realizados por Poeta e Rosa Neto (2005), utilizando atividades psicomotoras, comprovaram que, por meio da intervenção do professor de Educação Física, utilizando atividades psicomotoras, o aluno com TDAH apresenta progressos nas áreas motoras como: coordenação motora global, coordenação motora fina, equilíbrio, lateralidade, noção corporal, temporal e espacial, fundamentais para a realização de tarefas cotidianas, bem como, imprescindíveis nas atividades escolares e, por conseguinte, nos aspectos relacionados à aprendizagem.

Atividades de caráter lúdico são indicadas pela literatura como benéficas a crianças com diagnóstico de TDAH. Segundo Vygotsky (2001), por meio da ludicidade, a criança aprende a colocar em prática sua curiosidade, adquire iniciativa, autoconfiança, desenvolve a linguagem, pensamento e a concentração. A brincadeira é evidenciada por Lorenzini (2002) como um elemento da atividade lúdica que proporciona à criança experiências de ordem sensorial, motora, perceptual, cognitiva e cultural, necessárias ao desenvolvimento.

Cunha (2012) acrescenta que o lúdico é uma ferramenta eficaz para o ensino e a aprendizagem da criança com TDAH, pois minimiza os problemas de desatenção, inquietude, irritabilidade e comportamentos hiperativos. Nesse sentido, Viana (2013) sugere que recursos didáticos devem ser utilizados por contribuírem para a manutenção da atenção de crianças com o transtorno, estimularem a capacidade de criatividade, a participação ativa e efetiva, além de promoverem o prazer de brincar e a interação com os demais alunos.

\footnotetext{
${ }^{7}$ Segundo Manzini (2010) estratégia de ensino é uma ação que acontece no momento do ensino ou da avaliação do aluno. Porém, deve ser planejada anteriormente, levando em consideração as características da deficiência , as potencialidades do aluno, o objetivo que se pretende com a realizaçáo da atividade e o nível de complexidade da atividade exigida.

${ }^{8}$ Recurso pedagógico corresponde a um estímulo concreto, manipulável e que a esse estímulo seja atribuída uma ou mais finalidades pedagógicas (MANZINI; DELIBERATO, 2007).
} 
Outra atividade funcional para o trabalho junto à criança com TDAH refere-se aos jogos nas suas diversas formas. O estudo realizado por Lopes (2001) aponta que o jogo é uma ferramenta criativa, atraente e interativa que auxilia o professor a minimizar os problemas de desatenção e de comportamento social nas crianças hiperativas, potencializando a aprendizagem, consequentemente seu desenvolvimento integral.

Tintori, Bast e Pitta (2011) destacam a relevância do jogo no processo terapêutico com crianças sem e principalmente com TDAH. Adicionalmente, Barros (2002) acrescenta que os jogos são significativos, pois estimulam aspectos relacionados ao respeito ás regras, normas sociais e grupais, pois, ao jogar, as crianças estabelecem relaçóes inter e intrapessoais.

Entre outros estímulos, o jogo desperta em seus jogadores a necessidade de compreensão, atenção, antecipação, rapidez de pensamento para a formulação de estratégias e resolução de problemas (MACEDO; PETTY; PASSOS, 1997). Não obstante, Lopes (2001) comenta que o professor pode utilizar diversos recursos ao construir o jogo com seus alunos, e que o contato da criança com estes constitui-se como estímulos à adoção de novos hábitos comportamentais.

Neste pressuposto, surgiu uma inquietação que se traduziu em um dos problemas desta pesquisa, sendo ele: quais estratégias de ensino e recursos pedagógicos podem subsidiar uma intervenção junto a crianças com TDAH de modo a estimular a memória, atenção e concentração?

A partir deste problema a pesquisa teve como objetivo planejar, aplicar e analisar um programa de intervenção sistematizado, composto por atividades psicomotoras, lúdicas e jogos de estratégias a partir da adaptação de recursos pedagógicos e estratégias de ensino utilizadas em aulas de Educação Física com intuito de estimular a memória, atenção e concentração de crianças com Transtorno de Déficit de Atenção e Hiperatividade/Impulsividade.

Este estudo pretendeu oferecer subsídios para professores de Educação Física, partindo da hipótese de que a estruturar estratégias de ensino e recursos pedagógicos podem ampliar a prática docente e, por conseguinte, potencializar a aprendizagem dos alunos com TDAH e equiparar oportunidades em meio a diversidade de alunos que se encontram atualmente nas escolas regulares de ensino de todo o país.

\section{Metodologia}

A presente pesquisa caracteriza-se como uma "pesquisa-ação" que, segundo Tripp (2005), consiste em um ciclo no qual se lapida a ação pela oscilação entre o agir no campo da prática e o investigar sobre ela. Atendeu os requisitos éticos ${ }^{9}$, sendo realizada em uma escola municipal de ensino regular na cidade de Presidente Prudente/SP.

A pesquisa foi submetida à Secretaria Municipal de Educação (SEDUC) de Presidente Prudente/SP. Naquela ocasião, foi solicitado, junto a SEDUC, um mapeamento correspondente às escolas regulares que possuíam alunos que atendiam ao critério de inclusão, ou seja, possuir diagnóstico de TDAH, com predominância de desatenção, hiperatividade ou do tipo combinado e estar regularmente matriculados no Ensino Fundamental ciclo I e II.

\footnotetext{
${ }^{9} \mathrm{O}$ estudo foi encaminhado e aprovado pelo comitê de ética da faculdade de ciências e tecnologias UNESP campus de Presidente Prudente, seguindo as recomendaçóes vigentes na resolução CNS (Parecer no 388.159).
} 
Após este procedimento, foram identificadas as unidades que atendiam alunos com diagnóstico de TDAH para uma escolha aleatória. Nessa escola havia quatro estudantes que atendiam aos critérios, sendo três do sexo feminino e um do sexo masculino, com idades que variaram de seis a 10 anos, sendo que apenas um fazia uso de medicamentos. Com o consentimento da direção, foi realizada uma reunião com os pais dos alunos para esclarecimentos quanto à pesquisa. Dessa forma, os responsáveis pelos quatro alunos consentiram na participação de seus dependentes no estudo, por meio da assinatura de um termo de consentimento livre e esclarecido e de imagem.

Os dados foram coletados em duas etapas:

Etapa 1: planejamento e aplicação da Escala de Desenvolvimento Motor-EDM Proposta por Rosa Neto (2002) como pré-requisito para a elaboração das atividades. Na fase de planejamento foi selecionado um instrumento que possibilitasse a identificar as condiçóes motoras dos alunos. Nesse sentido, optou-se por utilizar a Escala de Desenvolvimento Motor proposta por Rosa Neto (2002), uma que vez a escala permite avaliar o desempenho motor nas áreas: motricidade fina (óculo manual); motricidade global (coordenação); equilíbrio (postura estática); esquema corporal (imitação postura e rapidez); organização espacial (percepção do espaço); organizaçáo temporal (linguagem e estruturas temporais) e lateralidade (mãos, olhos e pés), bem como, determinar o avanço ou atraso motor da criança de acordo com os resultados obtidos, além de comparar a idade motora com a idade cronológica. Outro fator determinante para escolha do instrumento diz respeito à faixa etária na qual a escala pode ser aplicada que correspondem indivíduos entre dois e 11 anos, o que contempla a idade das crianças participantes da pesquisa.

Os dados obtidos na EDM indicaram que os alunos apresentaram uma pontuação que variou de 76 a 90 pontos. Comparando os resultados obtidos com a classificação proposta pela EDM, os participantes do estudo apresentaram índices entre normal baixo e normal médio, visto que a classificação varia de muito inferior a muito superior. Com relação à área motora deficitária dos alunos em geral foram à motricidade global (coordenação) e o equilíbrio (postura estática). Nesse sentido, os dados resultantes da aplicação indicaram que os alunos possuíam atraso motor, bem como a necessidade de estímulos para o aprimoramento das áreas motoras deficitárias.

Etapa 2: planejamento e Aplicação do Programa de Intervenção. O delineamento das atividades ocorreu a partir de duas fases: a) os dados resultantes da aplicação do EDM indicaram que os alunos possuíam atraso motor em relação à idade cronológica e que as áreas deficitárias foram: motricidade global (coordenação) e o equilíbrio (postura estática), esse fato indicou a necessidade de intervençóes.

Esses dados serviram de parâmetros para nortear a elaboração das tarefas quanto ao propósito da atividade, especificidade e ao grau de complexidade com o intuito de proporcionar estímulos ao aprimoramento das áreas motoras em defasagem. B) Nesse ínterim, foi realizado um levantamento bibliográfico específico ao tema com o intento de identificar atividades pertencentes à área de Educação Física e que proporcionassem estímulos às capacidades motoras em atraso, apresentadas a partir dos resultados da EDM, levando em consideração alguns aspectos quanto ao tempo de duração da atividade, espaço, necessidade de recursos, bem 
como a especificidade quanto aos estímulos a memória, atenção e concentração de crianças com TDAH.

Partindo deste princípio, utilizou-se como aporte teórico para selecionar as atividades autores como: Cunha (2012), Fonseca (1984), Vygotsky (2011), Macedo, Petty e Passos (1997).

Após este procedimento, foram selecionados três eixos temáticos de atividades e realizadas 40 sessốes de intervençóes, conforme tabela que segue:

Tabela 1- Atividades desenvolvidas a partir dos eixos temáticos.

\begin{tabular}{l|l|l}
\hline Eixo Temático & Quantidade de Sessóes & Atividades Desenvolvidas \\
\hline Psicomotora (Circuito) & 13 Intervençóes & $\begin{array}{l}\text { Coordenação motora, equilíbrio, lateralidade, noção espa- } \\
\text { cial e temporal. }\end{array}$ \\
\hline Lúdicas & 14 Intervenções & Brincadeiras e construção do brinquedo. \\
\hline Jogos de Estratégia & 13 Intervençóes & Jogos de Mesa e construçấo de jogos. \\
\hline
\end{tabular}

Fonte: elaboração própria.

Todas as sessóes contaram com um planejamento prévio mediante um plano de aula e foram organizadas em eixos temáticos que se alternavam a cada duas sessóes, realizadas de forma grupal, duas vezes por semana, com duração média de uma hora cada. As intervenções tiveram como finalidade identificar e selecionar estratégias de ensino e recursos pedagógicos para intervir junto à criança com TDAH.

Para fins de registro de dados foi utilizada a filmagem. De acordo com Reyna (1997), este tipo de registro possibilita a análise de diferentes dados qualitativos e quantitativos por meio da observação do indivíduo em desenvolvimento em diferentes contextos. Uma das vantagens deste método é que outros pesquisadores ou colaboradores (juízes) também podem fazer uso do material coletado (KENSKI, 2003).

Foi utilizada uma câmera da marca JVC- Dynamic Zoom 45x, sob apoio de um tripé. Uma das preocupaçóes da pesquisadora foi onde posicionar a câmera para que esta pudesse estar em uma angulação que registrasse todos os momentos das intervençóes. Dessa forma, foram realizados testes iniciais para verificar a melhor disposição e após os testes a câmera foi posicionada no mesmo local em todas as intervençóes. No entanto, com vistas à necessidade de direcionamento da câmera em momentos específicos da tarefa, as intervençóes contaram com a presença de um estagiário para auxiliar na manipulação do equipamento.

A observação metodologicamente sistematizada também foi aplicada na pesquisa. Utilizou-se a Observação Participante nas aulas com o apoio das filmagens e registros em diário de campo. As filmagens foram norteadas por um roteiro previamente elaborado e executado nos momentos de observação. Este roteiro era composto por diferentes dados para observação, dentre eles: a rotina estabelecida, a organização espacial, o recurso utilizado nas aulas.

Posteriormente, as filmagens foram analisadas com o objetivo de identificar as estratégias de ensino e recursos pedagógicos utilizados durante a execução das aulas, como estímulos 
a memória, atenção e concentração, bem como de identificar comportamentos das crianças no que tange aos aspectos do transtorno, ou seja, de hiperatividade/impulsividade e desatenção. Após cada filmagem, foi documentado em diário de campo as diferentes açóes percebidas no decorrer da aula que não foram possíveis de serem registradas.

A análise dos dados foi composta por duas fases, a saber:

Fase I: análise de conteúdo segundo Bardin (2011). A partir das filmagens, as ocorrências foram descritas e, posteriormente, foi realizada uma leitura flutuante. Após este procedimento, classificou-se e categorizaram-se as transcriçôes no que diz respeito aos pontos mais relevantes, de acordo com a finalidade da pesquisa. Para a análise dos dados referentes às filmagens, foram utilizados os procedimentos específicos apontados por esta técnica de coleta de dados. Todas as intervençóes foram assistidas mais de três vezes. Segundo Loizos (2002), o filme deve poder ser visto por várias vezes e o material resultante deve ser analisado até que não se encontre novas descobertas e pontos intrigantes.

Fase II: apresentação dos "recortes" das filmagens ao juiz para avaliação das categorias. Solicitada a colaboração de um juiz, foram fornecidas informações para que ele observasse se as categorias e subcategorias elegidas, com as devidas estratégias e recursos alocados em cada uma delas, condiziam com as cenas das intervençóes. Após discussóes com o juiz, foram realizadas algumas adequaçóes apresentadas a seguir. Essas ações resultantes da aplicação do programa constituíram seis categorias, sendo cinco relativas às estratégias de ensino e uma categoria sobre recursos pedagógicos.

\section{Resultados E discussáo}

Após análise das observações com registro em diário de campo e filmagens, procedentes das 40 sessóes, foram identificadas seis categorias com suas respectivas subcategorias, as quais se apresentam a seguir.

\subsection{Categoria 1}

\section{VÍNCULO: PROFESSOR/ALUNO E ALUNO/ALUNO}

Foram identificadas três subcategorias: I) Dinâmicas em grupo, II) Identificação das atividades experiênciadas pelos alunos e III) Estímulos às experiências interpessoais entre os alunos.

As estratégias adotadas proporcionaram aos alunos reconhecerem-se pelo próprio nome, como primeiro procedimento de aproximação e como estímulo a memória e atenção. No decorrer das intervençóes, os alunos passaram a chamar uns aos outros pelos seus nomes e a perceber quando um dos companheiros de turma se ausentava das sessóes, o que nos possibilitou perceber a concepção de grupo estabelecida entre os mesmos.

Para conhecer as experiências motoras, vivenciadas pelos alunos, foram realizados questionamentos a respeito do conhecimento e vivência de atividades que fazem parte dos conteúdos da Educação Física. Nesses momentos, os alunos permaneciam atentos para responder as perguntas, o que oportunizou ocasióes em que expressaram suas idéias e compartilharam 
suas experiências. Como feedback, os estudantes apontaram diversas atividades e sugestôes sobre brincadeiras que gostariam de realizar.

Instigados pela pesquisadora, foram realizados diálogos sobre a importância do relacionamento interpessoal e entre eles e a pesquisadora. À medida que as opinióes eram manifestadas, a pesquisadora reforçava a necessidade de estabelecer uma boa relação com o outro, bem como, o "espírito" de equipe que deveria estar presente em todas as intervençóes por meio da cooperação entre os alunos. Assim, a preocupação com o outro e a necessidade de estarem próximos nas atividades demonstram que eles estabeleceram vínculos básicos para convivência em grupo.

Silva e Navarro (2012) mencionam que o professor ao intervir junto à criança, não deve preocupar-se apenas com o conhecimento a ser transmitido por meio de informaçóes aos alunos, ao contrário, o docente precisa considerar o aluno como um sujeito interativo e ativo no processo de construção do conhecimento. Este fato é possível quando o "olhar" do professor está voltado ao processo de construçáo da cidadania dos alunos que ocorre por meio das relaçóes entre os sujeitos.

No entanto, para que esse processo ocorra, é imprescindível que o professor estabeleça vínculo com os alunos e que estes possam estabelecer vínculo uns com os outros. Nessa relação, o professor possui um papel fundamental, pois o vínculo que ele constrói com a criança contribui para que o aluno sinta-se seguro e possa construir-se como sujeito criativo, pensante e autônomo (RIZZO, 2006).

\subsection{Categoria 2}

\section{Trabalho Cooperativo}

Foram identificadas duas subcategorias: I) Promover atividades com jogos cooperativos e II) Compartilhar recursos pedagógicos.

As estratégias adotadas possibilitaram aos alunos experenciarem atividades em grupos que tiveram como princípio a necessidade de compartilhar recursos, bem como, o auxílio do outro para a construçáo e execução das atividades. Os recursos pedagógicos ofertados, propositadamente pela pesquisadora, foram menores que o número de alunos, além disso, os estudantes foram organizados em duplas e trios que se alternavam a cada semana para pudessem se relacionar uns com os outros.

Durante as atividades, observou-se que o aluno desatento permaneceu mais atento à tarefa, pois sua colaboração na atividade e a relação com a outra criança exigiu sua interação ativa, já que a outra criança solicitava e necessitava de sua ajuda diante da estratégia imposta. Por sua vez, o aluno com hiperatividade, no decorrer das intervençóes, compartilhava informaçóes com o outro e esperava sua vez para falar e realizar a atividade.

O trabalho cooperativo provocou nos alunos o sentimento de partilha e uma maior proximidade, observada nas intervençóes pela disponibilidade dos alunos em levar, para intervenção, materiais a serem compartilhados com o grupo. Observou-se também a prontidão dos alunos para auxiliar os demais a realizarem a tarefa sem que a pesquisadora precisasse indicar esta condição. 
De acordo com Amaral (2007), o professor deve instigar a cooperação entre os alunos, uma vez que a cooperação pauta-se em relaçóes de reciprocidade nas quais os indivíduos resolvem tarefas e problemas juntos.

Nesse sentido, ambientes de aprendizagem cooperativos devem ser ofertados a todas as crianças e, em especial, para criança com TDH, pois ela aumenta a autonomia e, consequentemente, a motivação, pois os alunos com TDAH sentem-se mais motivados quando aprendem em meio aos amigos de turma. Essa experiência proporciona ao sujeito diversificadas vivências, dentre elas, o aprender a compartilhar, socializar e a preocupar-se com o outro (POZO, 2002).

\subsection{Categoria 3}

MediaÇấo

Foram identificadas três subcategorias: I) Encorajar o aluno a iniciar, permanecer $e$ terminar a atividade, II) Feedback do professor como estimulo para que o aluno realize a tarefa e III) Mediar conflitos.

As estratégias adotadas proporcionaram aos alunos estímulos nos momentos em que eles disseram ou demonstraram não se sentirem capazes para realizar a atividade. Esses momentos foram observados especialmente nas atividades de jogos. A estratégia adotada pela pesquisadora foi a utilização de estímulos verbais com palavras de incentivo que tiveram como intuito encorajar o aluno para realizar a atividade. Do mesmo modo, foi utilizado feedback positivo para demonstrar satisfação pelo trabalho realizado pelos alunos.

Além da falta de motivação para iniciar a atividade, durante as primeiras intervençóes, ocorreram conflitos entre os alunos no que diz respeito à organização. Em geral, eles necessitavam da mediação da pesquisadora para decidir qual posição que cada um iria ocupar ao desenvolver a tarefa. Nesses momentos, a pesquisadora sentava com os alunos no círculo central da quadra, indicava a posição que cada um teria na atividade, e as regras, inicialmente elaboradas, eram retomadas.

No decorrer das intervenções, os conflitos diminuíram ao passo que foi transferida a responsabilidade de assumir papéis e de organização das atividades aos discentes, que tiveram que resolver os conflitos em conjunto, uma vez que eles passaram a ter autonomia para resolução dos problemas. Os alunos se mostraram menos ansiosos e com um maior controle sobre seus impulsos e comportamentos.

Nesta instância, o professor deve reconhecer seu papel de mediador no processo de ensino e aprendizagem, ou seja, agir como intermediário entre os conteúdos da aprendizagem e a construção do conhecimento junto ao aluno, a partir de uma abordagem que valorize as suas potencialidades (SILVA; NAVARRO, 2012).

Para valorizar as competências dos alunos, o professor deve enfatizar suas qualidades, reconhecer e reforçar os pontos fortes, transmitir sentimentos de segurança e confiança, e estimular os alunos a serem autônomos para que cada vez mais possam tomar decisóes por si próprias (BARKLEY, 2008; VASCONCELOS et al., 2005). 
A capacidade de autoresponsabilização de um grupo aumenta quando ele ganha autoconfiança, ao passo que compartilha e vivencia situaçóes de êxito. A medida em que os alunos ganham experiência em trabalhos em grupo e segurança no controle da sua dinâmica, a necessidade de intervenção do docente, como mediador, tende a ser cada vez menor (PETERS, 2006).

\subsection{Categoria 4}

\section{Rotina}

Foram identificadas cinco subcategorias: I) Construção de regras; II) Organização dos materiais; III) Disposição dos alunos ao iniciar a atividade; IV) Apresentação da tarefa; V) Feedback professorlaluno e aluno/professor.

As estratégias adotadas proporcionaram aos alunos a compreensão das etapas que compreenderam as intervençóes e, desta forma, os alunos mostraram-se menos ansiosos, mais atentos e participativos.

Como primeira etapa da rotina, foram adotadas estratégias que possibilitaram um bom convívio com a pesquisadora e entre os alunos, ou seja, a construção de regras. Esse momento ocorreu junto com os alunos em situaçóes de diálogos, quando os alunos foram questionados quanto às regras presentes na escola, e a necessidade dessas para as intervençóes.

Todos os alunos tiveram a oportunidade de contribuir na elaboração das regras. A pesquisadora anotou as sugestóes dos alunos em uma cartolina para que fossem retomadas nas demais intervençóes. Como regras, foram estabelecidas três condiçóes na qual os alunos deveriam ficar em silêncio e atentos à explicação/demonstração da pesquisadora. Segundo Bauermeister (2009), os alunos, quando instigados a participarem da elaboração das regras, mostram-se participativos sugerindo uma série de regras e "puniçóes" a serem adotadas devido o não cumprimento das regras estabelecidas. Rizo e Rangé (2003) discorrem sobre a relevância da atuação do professor em construir em parceira com os alunos as regras de convivência, pois, quando o aluno participa ativamente desse processo, ele se sente importante e responsável por sua boa conduta e pela conduta dos demais, o que resulta em uma mudança satisfatória em seu comportamento.

O segundo passo adotado para estabelecer a rotina diz respeito ao momento em que antecedia as intervençóes. Como estratégia, os alunos auxiliavam a pesquisadora a retirar o material da sala de Educação Física e levá-lo até a quadra. Este procedimento também era realizado ao final das intervençóes.

Para iniciar as intervençóes, os alunos sentavam no círculo central da quadra em roda e de mãos dadas. Neste momento, o aluno com desatenção era estimulado pelo aluno com hiperatividade a estar concentrado durante a explicação/demonstração da atividade, enquanto, o aluno com hiperatividade necessitava conter sua agitação motora pela condição de estar de mãos dadas com os demais alunos da turma.

A pesquisadora, ao apresentar a tarefa, utilizava a explicação e demonstração conjuntamente. Além disso, para evitar a dispersão dos alunos, foram realizados questionamentos quanto à finalidade dos materiais para a realização da tarefa e a relação destes com materiais que faziam parte do cotidiano dos alunos. 
Ao final das intervençóes, a pesquisadora sentava com os alunos no círculo central da quadra e questionava sobre a atividade realizada, os desafios e facilidades vivenciadas durante a execução e o comportamento dos alunos no decorrer da intervenção. Após todos os alunos comentarem, a pesquisadora apresentava suas consideraçóes sobre os itens questionados.

Para Proença (2004), rotina é uma estrutura organizacional com finalidade pedagógica que possibilita ao professor promover atividades educativas sistêmicas e ainda aquelas que surgem espontaneamente por sugestão de um aluno ou da turma.

A rotina apresenta-se como elemento de suma importância para que os alunos possam se localizar no tempo e no espaço, além de ser um instrumento de aprendizagem (LIMA, 2010). Dias e Bhering (2004) acrescentam que o professor, ao estabelecer uma rotina, deve levar em consideração às necessidades dos alunos, o ambiente e as metas a serem alcançadas. Não obstante, é de suma importância a participação dos estudantes como sujeitos ativos e que a rotina possibilite espaços para as discussóes e expressóes de todos os integrantes do grupo, bem como, a internalização desta pelos sujeitos.

\subsection{Categoria 5}

\section{Recurso Pedagógico}

Foram identificadas três subcategorias: I) Seleção do recurso; II) Interação do aluno com o recurso e III) Utilizaçâo, construção e ou adaptação do recurso.

As estratégias adotadas para a seleção dos recursos foram planejadas de modo que elas pudessem chamar a atenção dos alunos e para que os alunos pudessem lembrar de situaçóes cotidianas em que o recurso se fazia presente afim de minimizar comportamentos de ansiedade e, por conseguinte, de agitação motora.

Foram selecionados jogos com desenhos atuais, ou seja, que fazem parte do cotidiano das crianças, o que facilitou a interação dos alunos com os recursos. Além disso, a pesquisadora, inicialmente, utilizou jogos com grau de complexidade baixo e aos poucos, estes foram aumentados gradativamente. Para verificar a complexidade do jogo, a pesquisadora utilizou critérios, como quantidade de peças, tamanhos, cores, formatos e texturas, de modo a estimular ao aluno a realizar a tarefa.

Diversos recursos foram disponibilizados aos alunos para que pudessem escolher aquele que mais agradar-lhe-ia para a realização da tarefa. Nestes momentos, foi possível observar que tanto a criança desatenta quanto a criança hiperativa estiveram atentas durante a escolha do recurso a ser utilizado e ao desenvolver a atividade, pois estavam de posse de recursos que mais lhe agradavam e, ainda, com a possibilidade de trocar caso julgasse necessário.

Adicionalmente, foram realizadas construçóes de jogos e brinquedos para as intervençóes. Estes momentos possibilitaram aos alunos expressarem e utilizarem sua criatividade e autonomia para criarem e recriarem diversos recursos. Nestas oportunidades, observou-se a importância que os alunos atribuem aos recursos produzidos por eles, expressos pela concentração que os alunos tiveram durante a fase de construção, assim como no decorrer da atividade na qual os alunos atribuíram significados e sentidos ao jogo/brinquedo construído. 
De acordo com Manzini (1999), o recurso pedagógico caracteriza-se com um estímulo concreto que possa a ser manipulável e que possui uma finalidade pedagógica, este deve ser selecionado e inserido ao ensino mediante o planejamento, ou seja, após a seleção dos procedimentos e técnicas.

Uma das funçóes do recurso pedagógico é o auxilio que ele pode desempenhar para o desenvolvimento do pensamento e da imaginação do aluno, ademais, o recurso aproxima o aluno a realidade e possibilita que o aluno extraia do recurso o que este pode contribuir para a sua aprendizagem (SCHMITZ, 1998).

Silva (2010) ressaltou que o recurso, por si só, não promove o ensino, é fundamental a presença do professor para fornecer oportunidades de aprendizagem aos alunos. Audi (2006) complementa que ao selecionar, construir ou adaptar um recurso, o docente deve levar em consideração às características individuais dos estudantes para que o recurso possa garantir o acesso do aluno à atividade e melhorar o seu desempenho na realização das tarefas.

\subsection{Categoria 6}

\section{AMBIENTE}

Foram identificadas três subcategorias: I) Escolha do local; II) Delimitação do local e III) Reconhecimento do local.

As estratégias adotadas para a seleção do ambiente possibilitaram que os alunos pudessem desenvolver a atividade sem grandes dispersóes.

Foram utilizados dois ambientes de intervenção, a quadra e a sala de aula. A quadra foi utilizada para atividades lúdicas e psicomotoras, enquanto que a sala foi utilizada para os jogos. Na quadra, algumas medidas foram adotadas para que os alunos não dispersassem com facilidade. Para tanto, a pesquisadora utilizou o círculo central e a área correspondente às demarcaçóes da quadra de voleibol.

Para que os alunos pudessem compreender a área a ser utilizada, esta foi sinalizada com fitas e cones e a pesquisadora, antes de iniciar a atividade, percorria o local junto com os alunos para que eles pudessem reconhecer o local e, dessa forma, ficarem menos ansiosos e mais concentrados para desenvolver a atividade.

$\mathrm{Na}$ sala de aula, foram realizadas modificações nas disposiçóes das carteiras, que deixaram de ser enfileiradas e passaram a serem dispostas ao lado e a frente uma das outras, sendo que os alunos sentavam de acordo com estas disposiçóes. Esse procedimento possibilitou ao aluno com desatenção receber estímulos visuais apenas dos demais alunos da turma que encontravam a sua frente e ao seu lado. Já a criança hiperativa teve que conter a sua agitação uma vez que o espaço foi reduzido e tinha demais alunos ao seu lado e também a sua frente.

$\mathrm{O}$ professor, ao selecionar o ambiente para a aula junto à criança com TDAH, deve escolher ambientes tranquilos, com poucos estímulos para diminuir a distração dos alunos (WINNICK, 2004). Em continuidade, Barkley (2008) acrescenta que estudos apontam que ambientes barulhentos e desorganizados se associam à menor capacidade de atenção para a realização do trabalho e a maiores níveis de comportamentos impulsivos com crianças com 
TDAH. O professor, nesse processo, deve propiciar ao aluno um ambiente que atenda as suas necessidades e proporcione condiçóes favoráveis ao aprendizado (BAUERMEISTER, 2009).

$\mathrm{O}$ ambiente ideal para que o aluno com TDAH possa aprender de maneira facilitada, em geral, deve ser um ambiente organizado e que possibilite ao aluno compreender e se localizar no espaço. O professor, nesse processo, deve propiciar ao aluno um ambiente que atenda as suas necessidades e proporcione condiçōes favoráveis ao aprendizado (BAUERMEISTER, 2009).

\section{Conclusáo}

Por todos os fatos mencionados, conclui-se que a pesquisa atingiu seu objetivo, uma vez que, por meio das atividades selecionadas, que fizeram parte das intervençóes, obteve-se como resultados categorias que compóem um programa de intervenção, que estimulou a memória, atenção e concentração dos sujeitos da pesquisa. Esse fato se deu devido à participação do aluno no processo de construção da intervenção, onde o mesmo teve a oportunidade de se expressar, usar sua criatividade.

Desta forma, percebe-se que a mediação do professor se faz necessário, porém é de fundamental importância que o docente paute sua prática em uma educação voltada para a independência e autonomia do sujeito. Concluímos também que o trabalho cooperativo para crianças com TDAH é de suma importância, pois exige a atenção e o controle da sua agitação motora ao se relacionar com o outro e que, neste processo, o professor também deve criar rotinas, estabelecer regras, selecionar um recurso adequado e um ambiente favorável para facilitar a aprendizagem do sujeito.

Durante as intervençóes, observamos que as atividades psicomotoras, lúdicas e jogos de estratégia se interligam, ou seja, complementam-se e possibilitam estímulos a memória, atenção e concentração.

Dessa forma, compreendemos, ao final da pesquisa, que o programa de intervenção foi favorável ao estímulo referente às condições de memória, atenção e concentração de alunos com TDAH e deixamos como contribuição para o professor de Educação Física o Programa de Intervenção para este possa contribuir com a prática docente junto à criança com TDAH.

\section{REFERÊNCIAS}

AMARAL, J. D. Jogos cooperativos. 2.ed. São Paulo: Phorte, 2007.

AMERICAN PSYCHIATRY ASSOCIATION (APA). Proposed DSM-5 Organizational structure and disorders names, 2011. Disponível em: <http://www.dsm5.org/proposedrevision/Pages/proposeddsm5-organizational-structure-and-disorder-names.aspx>. Acesso em: 10 jun. 2014.

AUDI, M. Estudo comparativo do comportamento motor de membro superior em encefalopatas que fazem uso de pulseira estabilizadora. 2006. 108f. Dissertação (Mestrado em Educação) - Faculdade de Filosofia e Ciências, Universidade Estadual Paulista, Marília, 2006.

BARDIN, L. Análise de conteúdo. São Paulo: Ediçôes 70, 2001.

BARKLEY, R. Transtorno de déficit de atenção/hiperatividade. Porto Alegre: Artmed, 2008.

BARROS, J. M. G. Jogo infantil e hiperatividade. Rio de Janeiro: Sprint, 2002. 
BAUERMEISTER, J. J. Hiperativo, impulsivo, distraído você me conhece? Guia para pais, professores e professionais sobre o déficit de atenção. São Paulo: Elevação, 2009.

CUNHA, A. C. T. Importância das atividades lúdicas na criança com hiperatividade e défice de atenção segundo a perspectiva dos professores. 2012. 101f. Dissertação (Mestrado em Ciências da Educação) Escola Superior de Educação João de Deus, Lisboa, 2012.

DIAS, J.; BHERING, E. A interação adulto/criança: foco central do planejamento na educação infantil. Rev Contrapontos, Itajaí, v.4, n.1, p.91-104, 2004. Disponível em: < http://www6.univali.br/ seer/index.php/rc/article/view/752>. Acesso em: 23 set. 2013.

FARAONE, S. V. et al. The worldwide prevalence of ADHD: is it an American condition? World Psychiatry, Canadá, v.2, n.2, p.104-113, 2003. Disponível em: < http://www.ncbi.nlm.nih.gov/ pubmed/16946911>. Acesso em: 23 maio 2013.

FONSECA, V. Uma introdução às dificuldades de aprendizagem. Lisboa: Notícias, 1984.

KENSKI, V. M. Aprendizagem mediada pela tecnologia. Revista Diálogo Educacional, Curitiba, v.4, n.10, p.47-56, 2003.

LIMA, A. E. O. A rotina na educação infantil e sua contribuição para a autonomia moral da criança. 2010. Dissertação (Mestrado em Educação Brasileira) - Universidade Federal do Ceará, Ceará, 2010. Disponível em: < http://www.lucianarizo.com.br/artigos/criancas_escola.pdf>. Acesso em: 20 out. 2013.

LOIZOS, P. Vídeo, filme e fotografias como documento de pesquisa. In: BAUER, M.W.; GASKELL, G. (Org.). Pesquisa qualitativa com texto, imagem e som: um manual prático. Petrópolis: Vozes, 2002. p.137-55.

LOPES, M. G. Jogos na educação: criar, fazer e jogar. 4.ed. São Paulo: Cortez, 2001.

LORENZINI, M. V. Brincando a brincadeira com a criança deficiente: novos rumos terapêuticos. Barueri: Manole, 2002.

MACEDO, L.; PETTY, A. L. S.; PASSOS, N. C. Quatro cores, senha e dominó: oficinas de jogos em uma perspectiva construtivista e psicopedagógica. 3.ed. São Paulo: Casa do Psicólogo, 1997.

MANZINI, E. J. Recursos pedagógicos para o ensino de alunos com paralisia cerebral. Revista Mensagem da Apae, n.84, v.36, p.17-21, 1999.

. Recurso pedagógico adaptado e estratégias para o ensino de alunos com deficiência física In: MANZINI, E. J.; FUJISAWA, D. S. (Org.). Jogos e recursos para comunicação e ensino na educação especial. Marília: ABPEE, 2010. p.117-138.

MANZINI, E. J.; DELIBERATO, D. Portal de ajudas técnicas: equipamento e material pedagógico para educação - recursos adaptados II. Brasília, DF: ABPEE/MEC/SEESP, 2007.

NEIRA, M. G. Educação física: desenvolvendo competências. São Paulo: Phorte, 2003.

ORGANIZAÇÃO MUNDIAL DA SAÚDE. Classificação de transtornos mentais e de comportamento da CID-10: descriçóes clínicas e diretrizes diagnósticas. Porto Alegre: Artes Médicas, 1983.

PEREIRA, H. S.; ARAUJO, A. P. Q. C.; MATTOS, P. Transtorno do déficit de atenção e hiperatividade (TDAH): aspectos relacionados à comorbidade com distúrbios da atividade motora. Rev Brasileira de Saúde Materna, Recife, v.5, n.4, p.391-402, 2005. Disponível em: < http://www.scielo.br/ pdf/rbsmi/v5n4/27757.pdf>. Acesso em: 10 maio 2013.

PETERS, L. L. Atividades em pequenos grupos na educação física: jogos de significaçôes. Psicologia em Estudo, Maringá, v.11, n.3, p.503-512, 2006. 
POETA, L. S.; ROSA NETO, F. Intervenção motora em uma criança com transtorno do déficit de atenção/hiperatividade (TDAH). Revista Digital Efdesportes, Buenos Aires, 2005 . Disponível em: < http://www.efdeportes.com/efd89/tdah.htm>. Acesso em: 14 ago. 2013.

POZO, J. I. Aprendizes e mestres: a nova cultura da aprendizagem. Tradução de Ernani Rosa. Porto Alegre: Artmed, 2002.

PROENÇA, M. A. R. A rotina como âncora do cotidiano na educação infantil. Pátio Educação Infantil, Porto Alegre, v.2, n.4, p.13-15, 2004.

RIZO, L.; RANGÉ, B. Crianças desatentas, hiperativas e impulsivas: como lidar com essas crianças na escola?. In: BRANDÃO, M.Z.S. et al. (Org.). Sobre o comportamento e cognição: a história e os avanços, a seleção por conseqüências em ação. Santo André: Esetec Editores Associados, 2003. v.11. p.422-432.

RIZZO, M. F. T. A importância do educador físico no desenvolvimento de uma criança com transtorno de déficit de atenção e hiperatividade (TDAH). Revista Mackenzie de Educação Física e Esporte, v.5, número especial, 2006. Disponível em: < http://editorarevistas.mackenzie.br/index.php/ remef/article/view/1901>. Acesso em: 12 fev. 2013.

REYNA, C. P. Video e pesquisa antropológica: encontros e desencontros. Biblioteca on-line de Ciências da Computação. 1997. Disponível em: < http:www.bocc.ubi.pt>. Acesso em: 10 maio 2013.

ROHDE, L. A. et al. ADHD in a school sample of Brazilian adolescents: a study of prevalence, comorbid conditions and impairments. J Am Acad Child Adolesc Psychiatry, v.38, p.716-722, 1999. Disponível em: < http://www.scielo.br/scielo.php?script=sci_nlinks\&ref=000113\&pid=S01016083200500060000300045\&lng=en>. Acesso em: 20 ago. 2013.

ROHDE, L. A.; HALPER, N. R. Transtorno de déficit de atenção/hiperatividade: atualização. Jornal de Pediatria, v.80, n.2, supl., 2004. Disponível em: < http://www.scielo.br/pdf/jped/v80n2s0/ v80n2Sa08.pdf>. Acesso em: 16 fev. 2013.

ROSA NETO, F. Manual de avaliação motora. Porto Alegre: Artmed, 2002.

SILVA, A. B. B. Mentes inquietas: TDH: desatenção, hiperatividade e impulsividade. Rio de Janeiro: Objetiva, 2009.

SILVA, M. O. Protocolo para prescrição ou adaptação de recursos pedagógicos para alunos com paralisia cerebral. 2010. Dissertação (Mestrado em Educação) - Faculdade de Filosofia e Ciências da Universidade Estadual Paulista, Marília, 2010.

SILVA, O. G.; NAVARRO, E. C. A. A relação professor-aluno no processo ensino-aprendizagem. Revista Eletrônica Interdisciplinar da Univar, v.3, n.8, p.95-100, 2012. Disponível em: <http://www. univar.edu.br/revista/downloads/relacaoprofessor_aluno_processo.pdf>. Acesso em: 20 out. 2013.

SCHMITZ, H. Responding to global competitive pressure: local co-operation and upgrading in the Sinos Valley, Brazil. Institute of Development Studies, working paper, 1998.

SUZUKI, S.; GUGELMIM, M. R. G.; SOARES, A. V. O equilíbrio estático em crianças em idade escolar com transtorno de déficit de atenção/hiperatividade. Fisioterapia em Movimento, Curitiba, v.18, n.3, p.49-54, 2005. Disponível em: < http://www2.pucpr.br/reol/index.php/ rfm?dd1=216\&dd99=view>. Acesso em: 20 jun.2013.

TINTORI, F; BAST, D. F.; PITTA, M. R. Jogo na terapia comportamental em grupo de crianças com TDAH. Acta comportamentalia, v.19, n.2. p.225-239, 2011. Disponível em: < http://pepsic.bvsalud. org/scielo.php?pid=S0188-81452011000200006\&script=sci_arttext>. Acesso em: 12 maio 2013. 
TRIPP, D. Pesquisa-ação: uma introdução a metodológica. Revista Educação e Pesquisa, São Paulo, v.31, n.3, p.443-466, 2005. Disponível em: < http://www.scielo.br/pdf/ep/v31n3/a09v31n3.pdf>. Acesso em: 10 dez. 2013.

VASCONCELOS, A. A. et al. A presença do diálogo na relação professor-aluno. In: COLÓQUIO INTERNACIONAL PAULO FREIRE, 5., 2005, Recife. Anais... Recife, 2005. p.2-12.

VYGOTSKY, L. S. Psicologia pedagógica. São Paulo: Martins Fontes, 2001.

WINNICK, J. P. Educação física e esportes adaptados. Barueri: Manole, 2004.

Recebido em: 10/07/2014

Reformulado em: 05/03/2015

Aprovado em: 06/03/2015 